Journal of Economics and Behavioral Studies

Vol. 5, No. 12, pp. 851-860, Dec 2013 (ISSN: 2220-6140)

\title{
The Term Structure of Interest Rates: A Cointegration Analysis in the Non-Linear STAR Framework
}

\author{
Pelin ÖGE GÜNEY \\ Hacettepe University, Beytepe, Ankara, Turkey \\ pelinoge@hacettepe.edu.tr
}

\begin{abstract}
This paper analysis the term structure of interest rates for the Group of Seven (G7) countries. In addition to standard cointegration testing procedures, a cointegration test in a nonlinear smooth transition autoregression (STAR) framework developed by Kapetanios et al. (2006) is also employed. While the standard cointegration test results suggest the existence of cointegration relationship between short and long-term interest rates for Canada, France, Italy, Japan, and US data, these tests fail to establish a cointegration relationship for Germany and the United Kingdom. In case we take account of cointegration with non-linear adjustment, the results provide clear evidence of cointegration for all countries except Germany. Our finding implies that, especially in the case of UK, we may achieve important implications by taking account of possible nonlinearities. Overall, our findings support the proposition of expectation hypothesis for all of the G7 countries except Germany.
\end{abstract}

Keywords: Term Structure, Non-linear Models, Expectation Hypothesis

\section{Introduction}

The expectation hypothesis of the term structure of interest rates suggests that long-term interest rate is determined by the average of current and expected future short-term interest rates. This hypothesis has an important implication for economics and finance. First, expectation hypothesis is central for explanation of the effectiveness of monetary policy. Monetary authorities are able to influence short-term interest rates as documented in the empirical literature (e.g. Christiano and Eichenbaum, 1992; Leeper and Gordon, 1992). However, investment decisions of firms and capital assets prices are affected by long-term rates. The expectation hypothesis implies that monetary authorities can control long-term interest rates by influencing short-term interest rates. Hence, investigations of the link between short and long-term rates are important for policymakers. Second, the validity of the expectation hypothesis is related to the notion of market efficiency. Market efficiency implies that economic agents use all available information in forming expectations and movements in forward rates reflects these expectations. Therefore, expectation hypothesis requires that unexploited profit opportunities should not remain since long term rates are unbiased predictors of short-term rates, consistent with the market efficiency. Third, the term structure of interest rates provides a useful forecast of future economic variables such as inflation, economic activity and the direction of future changes in short-term rates (See Mishkin, 1990; Fama, 1990; Estrella and Hardouvelis, 1991; Hu, 1993; Bernard and Gerlach, 1996; Caporale and Pittis, 1998; Fama and Bliss, 1987; Hardouvelis, 1988).

Campbell and Shiller (1987) claimed that the expectation hypothesis requires a cointegrating relationship between long term and short-term interest rates. Subsequently, many studies tested the validity of expectation hypothesis focusing on the cointegration properties of the term structure. Hall et al. (1992) tested expectation hypothesis for the US and found evidence in favor of expectation hypothesis. Siklos and Wohar (1996) found evidence in favor of the expectation hypothesis for nine developed economies including the G7 countries. Taylor (1992) tested the term structure of interest rate for the UK. His results do not support the expectation hypothesis. Mustafa and Rahman (1995) also rejected the expectation hypothesis for the US. Hardouvelis (1994) examined the G-7 countries during the 1968-1992 and provided some explanations for the failure of the expectation hypothesis for these countries. These studies employed conventional methods developed by Campbell and Shiller (1987), Engle and Granger (1987) and Johansen 
(1988) that assume that adjustment are linear. However, as suggested by Balke and Fomby (1997), Granger and Terasvirta (1993), Michael et al. (1997) and Psaradakis et al. (2004), among others, most economic and financial variables follow nonlinear dynamics. Economic theory provides several reasons for asymmetric or non-linear adjustment process between the long-term and short-term interest rates. Anderson (1997) stated that transaction costs are one of the reasons of nonlinear adjustment. Expected profits are driving force of arbitrage. However, arbitrage does not work perfectly due to transaction costs. In fact, investors do not engage in arbitrage if deviation from the equilibrium is small. Arbitrage occurs only when the deviation is large enough to provide a profit after transaction costs. Bonds with different maturity may have different transaction costs. These costs could change during the time. Bachmeier and Li (2002) state that if the traders prefer short-term bonds, there would be a cost of accepting a longer maturity bond in addition to transaction cost. This implies that large difference in maturities will also cause to nonlinearity. Anderson (1997) and Fama (1990) argued that time-varying risk-premium might also exhibit non-linear behavior. According to Mankiw and Miron (1986), when the variable risk premium exist, the long-term interest rate will contain information about both future short-term rates and a time-varying risk premium.

Further, Enders and Granger (1998) and Sarno and Thornton (2003) pointed that the dynamic adjustment of the term structure to deviations from equilibrium may be asymmetric. Such asymmetric adjustment may also arise from asymmetric response of monetary policy authority to various shocks. As Kuo and Enders (2004) suggest, the response of monetary policy to positive deviation versus negative deviation from long run equilibrium inflation rate might be different. When the central bank's primarily aim is to maintain commitment to low inflation level, it might react to increase in inflation rate more strongly than to a decrease. Indeed, as Anderson (1997) and Hansen and Seo (2002) suggests, the theory of term structure does not imply the linear adjustment. These arguments indicate that the mentioned conventional procedures may not be able to detect a long run equilibrium relationship between short term and long-term interest rates. Consistent with these developments, several unit root tests against threshold autoregressive (TAR) alternatives have been proposed in the empirical literature, e.g. Enders and Granger (1998), Caner and Hansen (2001), Kapetanios and Shin (2006). However, there are few studies that directly test cointegration against nonlinear alternatives (e.g. Gallagher and Taylor, 2001; Hansen and Seo, 2002). In this paper, we use a new cointegration testing procedure in the nonlinear smooth transition autoregressive (STAR) framework developed by Kapetanios et al. (2006). This method allows identifying the presence of cointegrating relationship that follows a globally stationary smooth transition process. The STAR model considered by Kapetanios et al. (2006) exhibits explosive behavior near equilibrium. On the other hand, if deviation from equilibrium is large, it displays stable dynamic with quick convergence. Smooth transition autoregressive (STAR) model is the most appropriate model to analyze the nonlinear adjustment in the term structure of the interest rates. As emphasized by Anderson (1997) and Kapetanios et al. (2006), when transaction costs exist, arbitrage occurs only when disequilibrium in the bill market reaches to a level which implies net profits to investors after transaction costs. In this situation, a greater proportion of investors find the prospect of arbitrage profitable. This implies that when the yield spread from equilibrium is not large enough, the possible tendency to move back to the equilibrium is slowly.

On the other hand, if this spread is large the adjustment is quick. Therefore, when transaction costs exist, it is more reasonable to use nonlinear adjustment process for the term structure. Another point considered by Anderson (1997) is that it is possible that transaction costs vary across market participants. If different market participants have different thresholds arising from transaction costs, smoothly adjusted model is required. Kapetanios et al. (2006) also showed that their proposed nonlinear test have superior power compared to the linear tests. Recently many studies have detected nonlinearity in the adjustment processes of the interest rates. For example, Anderson (1997) found nonlinear adjustment in the U.S. Treasury bill market. Enders and Granger (1998) and Enders and Siklos (2001) reported evidence in favor of asymmetric momentum threshold adjustment process for the U.S. interest rates. Bachmeier and Li (2002) and Hansen and Seo (2002) have estimated nonlinear relationship of the term structure of the U.S. interest rate. Clarida et al. (2006) found presence of nonlinearities and asymmetries in the term structure for Germany, Japan and US data. Kuo and Enders (2004) and Maki (2006) reported non-linear adjustment in the term structure of Japanese interest rates. These studies find that although there is a long run equilibrium relationship between 
short term and long-term interest rates, this adjustment process may be non-linear in some of the developed countries.

Although there are some studies for the US in the literature, only limited research exist for other developed countries which consider the nonlinear adjustment in the term structure of the interest rate. Additionally, existing studies use different econometric methods, different time periods and different interest rate maturities. In this paper, we analyze the term structure of interest rates for the G7 countries, namely for Canada, France, Germany, Italy, Japan, U.K., and U.S. To enhance the comparability of the results from these countries we use similar data series and same econometric methods for all countries for the 1980-2012 periods. The government bond is employed as a long-term interest rate and Treasury bill rates as a shortterm interest rate. Taking account of the fact that the adjustment process may be inherently nonlinear, in addition to the conventional linear testing procedures of Engle and Granger (1987) and Johansen and Juselius (1990), we also apply nonlinear cointegration test developed by Kapetanios et al. (2006). There are some developments in the financial markets and changes in the policy regime in G7 countries during the analyzed period. For example, financial markets are deregulated in the second half of the 1980s in Japan. Canada and the UK adopted inflation targets in the 1990s. The ERM (The European Exchange Rate Mechanism) was created. Such changes may also cause to nonlinearity in the adjustment process. Nonlinear relationship means that long-term rate will asymmetrically respond to a change in the short-term rate. Nonlinearity has important implications for the central bank's ability to influence long-term rates. The results of the both Engle and Granger (1987) and Johansen and Juselius (1990) cointegration tests suggest a long run equilibrium relationship between short term and long term interest rates for Canada, France, Italy, Japan, and U.S. However, cointegration relationship was not found for Germany, and the United Kingdom. When we apply the test procedure of Kapetanios et al. (2006), we find a nonlinear cointegration between short-term and longterm interest rates for all countries except Germany. These results provide a supporting evidence for the expectation hypothesis. This paper is organized as follows. Section II presents the implications of the expectation hypothesis. Section III outlines the cointegration methodologies in subsequent empirical testing. Section IV describes the data and empirical results. Section V summarizes the main conclusions.

\section{The Expectation Hypothesis}

The general statement of expectation hypothesis is expressed by Hall et al. (1992) as follows:

$$
R_{k, t}=\frac{1}{k} \sum_{j=1}^{k} E_{t} R_{1, t+j-1}+\gamma_{k, t}
$$

Where $R_{k, t}$ express the time $t$ log compounded yield to maturity on a $k$ period pure discount bond, $E_{t}$ is the expectation operator conditioned on information available at time $t$, and $\gamma_{k, t}$ denotes the $k$-period term premium. Eq. (1) suggests that the long-term interest rate is equal to average of current and expected future short-term interest rates, plus a term premium. Term premium reflects investors' risk considerations and preferences for liquidity. According to the pure expectation hypothesis, the term premium is zero, while it is constant (or stationary) over time according to more general versions of the hypothesis.

If one subtracts $R_{1, t}$ from both sides of the Eq. (1) one obtains the following equation:

$$
S_{k, t} \equiv R_{k, t}-R_{1, t}=\frac{1}{k} \sum_{j=1}^{k-1} \sum_{j=1}^{j=i} E_{t} \Delta R_{1, t+j-1}+\gamma_{k, t}
$$

Where $\Delta$ is the first difference operator? Then the expectation hypothesis can be tested using Eq. (2). If $R_{k, t}$ and $R_{1, t}$ are integrated of order one, and if the premium $\gamma_{k, t}$ are stationary, the yield spread, $S_{k, t} \equiv R_{k, t}-R_{1, t}$ must be stationary. Hence, expectation hypothesis predicts that the interest rates in 
different periods are cointegrated with a cointegrating vector of the form $(1,-1)^{\prime}$. This in turn implies that if we have $\mathrm{N}$ interest rates of different maturities, exactly $\mathrm{N}-1$ independent cointegration relationship must exist among them. Each of these cointegrated vectors are given by the stationary spread $R_{k, t}-R_{1, t}$ for $\mathrm{k}=2, \ldots, \mathrm{N}$.

\section{Methodology}

Linear Cointegration Test: We first consider the Johansen and Juselius (1990) procedure to test for the long run relationship between variables. He proposes to use a VAR-based cointegration test to estimate multiple cointegration vectors.

Consider a VAR of order $p$ :

$X_{t}=\mu+A_{1} X_{t-1}+\ldots+A_{k} X_{t-k}+\varepsilon_{t}$

$\mathrm{t}=1,2, \ldots, \mathrm{T}$

Here $X_{t}$ is $(1+n)$ vector of $I(1)$ variables, $\mu$ is an intercept vector and $\varepsilon_{t}$ is $(1 x n)$ vector of error terms.

Eq. (3) may be rewritten as

$\Delta X_{t}=\mu+\Gamma_{k-1} \Delta X_{t-k+1}+\ldots+A X_{t-k}+\varepsilon_{t}$

Where $\Gamma_{i}=-\left(I-A_{1}-\ldots A_{i}\right)$ for $i=1, \ldots, k-1$ and $A=-\left(I-A_{1}-, \ldots, A_{k}\right)$

The rank of the $(n x n)$ coefficient matrix $A$ determines the number of cointegrating vectors among the variables in $X$.

If the matrix $A$ is of zero rank, this implies the absence of cointegration relationship between the variables in $X_{t}$. If $A$ is full rank, that is $r=n$, the variables in $X_{t}$ are stationary and if $A$ is of reduced rank $r<n$, then there exist nxr matrices $\alpha$ and $\beta$ each with $\operatorname{rank} r$ such that $A=\alpha \beta$ and the linear combination given by $\beta^{\prime} y_{t}$ is $I(0) . r$ is the number of cointegrating relationships.

Johansen and Juselius propose two different likelihood ratio tests for the determination of the number of cointegrated vectors: the trace test and maximum eigenvalue test, shown in Eq. (5) and (6) respectively.

$$
\begin{aligned}
& \lambda_{\text {trace }}=-T \sum \ln (1-\lambda i) \\
& \lambda_{\text {max }}=-T \ln (1-\lambda r+1)
\end{aligned}
$$

here $\lambda r+1, \ldots, \lambda n$ are the $n-r$ smallest squared canonical correlations and $T$ is the sample size.

The trace test tests the null hypothesis of $r$ cointegrating vectors against the alternative hypothesis of $n$ cointegrating vectors. The maximum eigenvalue test, on the other hand, tests the null hypothesis of $r$ cointegrating vectors against the alternative hypothesis of $1+r$ cointegrating vectors.

To apply the Johansen cointegration test procedure a lag length must be selected for the VAR. A lag length of one is selected based on the Akaike Information Criterion (AIC).

If linear adjustment is assumed, this approach is an appropriate way to examine the term structure of the interest rates. However, this framework is mis-specified if the adjustment process is nonlinear.

Nonlinear Cointegration Test: Kapetanios et al. (2006) consider following nonlinear vector error correction (VEC) model,

$$
\Delta z_{t}=\alpha u_{t-1}+g\left(u_{t-1}\right)+\sum_{i=1}^{p} \Gamma_{i} \Delta z_{t-i}+\varepsilon_{t}
$$

where $\mathrm{t}=1,2, \ldots, \mathrm{T}, z_{t}=\left(y_{t}, x_{t}\right), \alpha$ is an $n x 1$ vector of adjustment parameters and $u_{t}=y_{t}-\beta_{x} x_{t}, \beta_{x}$ is a $k x 1$ vector of cointegration parameters. The nonlinear function in Eq. (7) is assumed to be of exponential smooth transition functional form, 
$g\left(u_{t-1}\right)=-\varphi u_{t-1} e^{-\theta\left(u_{t-1}-c\right)^{2}}$

where $\theta \geq 0$ and $c$ is a transition parameter. Substituting Eq. (8) into Eq. (7), we obtain the following exponential smooth transition regression error correction model for $\Delta y_{t}$ and the marginal vector autoregression (VAR) model for $\Delta x_{t}$ :

$$
\begin{aligned}
& \Delta y_{t}=\phi u_{t-1}+\gamma u_{t-1}\left(1-e^{-\theta\left(u_{t-1}-c\right)^{2}}\right)+\omega \Delta x_{t}+\sum_{i=1}^{p} \psi_{i} \Delta z_{t-i}+e_{t} \\
& \Delta x_{t}=\sum_{i=1}^{p} \Gamma_{x i} \Delta z_{t-i}+\varepsilon_{x t}
\end{aligned}
$$

where $\omega \equiv \sum_{x x}^{-1} \sigma_{x y}$ and $\psi_{i} \equiv \gamma_{y i}-\omega \Gamma_{x i}, \mathrm{i}=1, \ldots, \mathrm{p}$. Kapetanios et al. (2006) proposed that the null of no cointegration against the alternative of globally stationary cointegration can be expressed as follows:

$$
\begin{aligned}
& H_{0}: \theta=0 \\
& H_{1}: \theta>0
\end{aligned}
$$

However, testing the null hypothesis directly is not feasible since the parameter $\gamma$ is not identified under the null. To overcome this problem and derive a t-type test statistic, Kapetanios et al. (2003) replace the transition function $g\left(u_{t-1}\right)=1-e^{-\theta\left(u_{t-1}-c\right)^{2}}$ by its first-order Taylor approximation around $\theta=0$, yielding the auxiliary regression under the assumption that $\phi=0$ :

$$
\Delta y_{t}=\delta u_{t-1}^{3}+\omega \Delta x_{t}+\sum_{i=1}^{k} \gamma \Delta y_{t-i}+\sum_{i=1}^{k} \varphi \Delta x_{t-i}+e_{t}
$$

The $t_{N E C}$ test is based on the test statistic for $\delta=0$ against $\delta<0$ obtained from Eq. (11). Kapetanios et al. (2003) also consider a test that is similar to the Engle-Granger test. It is based on the following regression:

$\Delta u_{t}=\delta u_{t-1}^{3}+\sum_{i=1}^{p} \beta_{i} \Delta u_{t-i}+e_{t}$

$t_{N E G}$ is based on the test statistic for $\delta=0$ against $\delta<0$.

\section{Results}

In this paper, we use ten-year government bond as a long-term interest rate, and three-month treasury bill rates or call rates as a short-term interest rate. The monthly data collected from International Financial Statistics database for the period from 1980:1-2012:3. The sample covers some important changes in the financial markets. For example, the ERM (The European Exchange Rate Mechanism) was created. France and Italy maintained some form of capital control during some periods. On the other hand, the capital controls were relaxed in Japan and the UK. In addition, significant changes in monetary policy strategies have occurred. For example, Canada, and the UK adopted inflation targets in the 1990s. Table 1 summaries the data used in this study and Figure 1 presents the graph of the short term and long-term rates.

Table 1: List of Countries Studied

\begin{tabular}{llll}
\hline Country & Sample Period & Long term interest rate & Short term interest rate \\
\hline Canada & $1980: 1-2012: 3$ & Government Bond Yield & Treasury Bill Rate \\
France & $1980: 1-2012: 3$ & Government Bond Yield & Treasury Bill Rate \\
Germany & $1980: 1-2007: 8$ & Government Bond Yield & Treasury Bill Rate \\
Italy & $1980: 1-2012: 3$ & Government Bond Yield & Treasury Bill Rate \\
Japan & $1980: 1-2012: 3$ & Government Bond Yield & Treasury Bill Rate \\
UK & $1980: 1-2012: 1$ & Government Bond Yield & Treasury Bill Rate \\
US & $1980: 1-2012: 3$ & Government Bond Yield & Treasury Bill Rate \\
\hline
\end{tabular}




\section{Figure 1: The Short Term Rate (SR) and Long Term Rate (LR)}
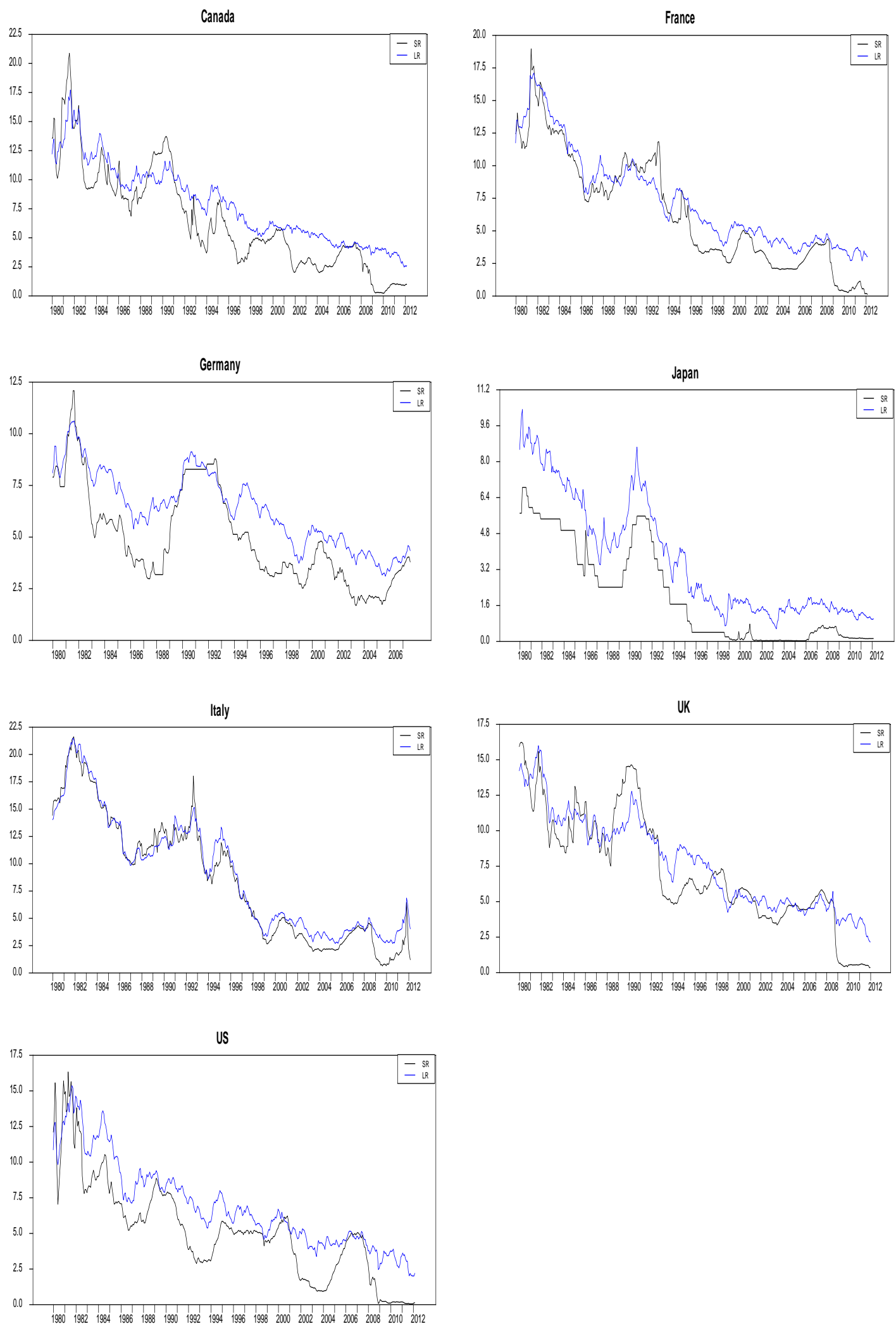
In order to examine the time series properties of the variables in question we first employ unit root tests. The results of Augmented Dickey Fuller (ADF) unit root tests of the short term and long-term interest rates are given in Table 2 . All tests include only a constant as a deterministic component. It can be seen from the Table 2 that interest rate series are non-stationary for all countries.

Table 2: Augmented Dickey Fuller Unit Root Test Results

\begin{tabular}{lll}
\hline Country & S- Rate & L- Rate \\
\hline Canada & -1.822 & -0.795 \\
France & -1.213 & -0.873 \\
Germany & -1.729 & -1.182 \\
Italy & -0.885 & -0.967 \\
Japan & -1.477 & -1.684 \\
UK & -1.796 & -1.510 \\
US & -2.146 & -0.936 \\
\hline
\end{tabular}

Notes: L-Rate and S-Rate denote long-term and short-term interest rates, respectively.

The Johansen maximum eigenvalue and trace test statistics for cointegration among short and long-term interest rates are reported in Table 3.

Table 3: Johansen's Cointegration Test Results

\begin{tabular}{|c|c|c|c|c|c|c|}
\hline Country & $\begin{array}{l}\text { Null } \\
\text { Hypothesis }\end{array}$ & Trace & & $\begin{array}{l}\text { Null } \\
\text { Hypothesis }\end{array}$ & L-Max & \\
\hline & & Test Statistics & $p$-value & & Test Statistics & p-value \\
\hline \multirow[t]{2}{*}{ Canada } & $\mathrm{r}=0$ & $17.863^{* *}$ & 0.021 & $r=0$ & 17.052 & $0.018^{* *}$ \\
\hline & $r \leq 1$ & 0.811 & 0.368 & $\mathrm{r}=1$ & 0.811 & 0.368 \\
\hline \multirow[t]{2}{*}{ France } & $\mathrm{r}=0$ & $14.752^{* * *}$ & 0.065 & $r=0$ & 13.572 & $0.064^{* * *}$ \\
\hline & $r \leq 1$ & 1.180 & 0.278 & $\mathrm{r}=1$ & 1.180 & 0.278 \\
\hline \multirow[t]{2}{*}{ Germany } & $\mathrm{r}=0$ & 8.975 & 0.368 & $\mathrm{r}=0$ & 6.859 & 0.506 \\
\hline & $r \leq 1$ & 2.116 & 0.146 & $\mathrm{r}=1$ & 2.116 & 0.146 \\
\hline \multirow[t]{2}{*}{ Italy } & $\mathrm{r}=0$ & $14.630^{* * *}$ & 0.067 & $r=0$ & 13.746 & $0.060^{* * *}$ \\
\hline & $r \leq 1$ & 0.884 & 0.347 & $\mathrm{r}=1$ & 0.884 & 0.347 \\
\hline \multirow[t]{2}{*}{ Japan } & $r=0$ & $31.679^{*}$ & 0.000 & $\mathrm{r}=0$ & 28.956 & $0.000^{*}$ \\
\hline & $r \leq 1$ & 2.723 & 0.099 & $\mathrm{r}=1$ & 2.723 & 0.099 \\
\hline \multirow[t]{2}{*}{ UK } & $\mathrm{r}=0$ & 12.631 & 0.129 & $r=0$ & 10.676 & 0.171 \\
\hline & $r \leq 1$ & 1.955 & 0.162 & $\mathrm{r}=1$ & 1.955 & 0.162 \\
\hline \multirow[t]{2}{*}{ US } & $r=0$ & $16.837^{* *}$ & 0.031 & $r=0$ & 15.200 & $0.035^{* *}$ \\
\hline & $r \leq 1$ & 1.636 & 0.200 & $r=1$ & 1.636 & 0.200 \\
\hline
\end{tabular}

Notes: $\left({ }^{*}\right)$ significant at a $1 \%$ level, $\left({ }^{* *}\right)$ significant at a $5 \%$ level; $\left({ }^{* * *}\right)$ significant at a $10 \%$ level.

Trace and L-max denote trance and maximum eigenvalue tests, respectively.

A lag length is selected based on the Akaike Information Criterion (AIC).

The results show the existence of one cointegrating vector for Canada, France, Italy, Japan, and US data. However, the Johansen procedure is not able to detect a long run equilibrium relationship between interest rate series for Germany and the United Kingdom. In Table 4, the first row of the table refers to the Engle and Granger (EG) tests. This method also fails to obtain the cointegration relationship for Germany and the United Kingdom, similar to Johansen and Juselius (1990) test. On the other hand, the test results of nonlinear cointegration test developed by Kapetanios et al. (2006) provide clear evidence of cointegration for all 857 
countries except Germany as reported in Table 4. The results suggest that discrepancies from long-term equilibrium for United Kingdom might be inherently nonlinear.

Table 4: Cointegration Test Results in the Engle Granger and STAR Framework

\begin{tabular}{llll}
\hline Country & $\boldsymbol{E G}^{\boldsymbol{a}}$ & $\mathbf{t}_{\mathrm{NEC}} \mathbf{b}^{\mathbf{b}}$ & $\mathbf{t}_{\mathbf{N E G}} \mathbf{c}^{\mathbf{c}}$ \\
\hline Canada & $-3.455^{* *}$ & $-3.024^{* * *}$ & $-4.061^{*}$ \\
France & $-3.359^{* * *}$ & -0.443 & $-3.626^{* *}$ \\
Germany & -2.083 & -2.002 & -2.221 \\
Italy & $-4.066^{*}$ & $-3.918^{*}$ & $-4.998^{*}$ \\
Japan & $-7.422^{*}$ & $-3.424^{* *}$ & $-7.620^{*}$ \\
UK & -2.796 & -2.483 & $-3.747^{* *}$ \\
US & $-3.937^{*}$ & $-5.109^{*}$ & $-4.281^{*}$ \\
\hline
\end{tabular}

Notes: $\left(^{*}\right)$ significant at a $1 \%$ level, $\left({ }^{* *}\right)$ significant at a $5 \%$ level; $\left({ }^{* *}\right)$ significant at a $10 \%$ level.

a 10, 5, and 1\% critical values obtained from Phillips and Ouliaris (1990) equal -3.06, -3.36, and -3.91, respectively.

b 10, 5, and 1\% critical values obtained from Kapetanios et al. (2006) equal -2.92, -3.22 and -3.78, respectively.

c 10, 5, and 1\% critical values obtained from Kapetanios et al. (2006) equal -2.98, -3.28, and -3.84, respectively

The link between long-term interest rates and the expectations about the path of the short-term interest rates provide information about the response of long-term interest rates to central bank polices. If the expectations theory holds, then central banks can influence long-rates through short-term rates. In our paper, according to conventional cointegration tests, cointegration relationship was not found for Germany, and the United Kingdom. There are several reasons, i.e. transaction costs, time-varying risk-premia, changes in policy regimes to analyze nonlinear adjustment process between the long-term and short-term interest rates. Hence, the empirical failure of the expectation hypothesis may result from nonlinearity. By taking into account the nonlinearity in the term structure, we apply nonlinear cointegration test. Our results provide evidence supporting nonlinear cointegration relationship between short-term and long-term interest rates for all countries except Germany. This implies that the effects of monetary policy might be asymmetric, especially in the case of UK. This result is consistent with the findings of the Nelson (2001) and Bianchi et al. (2009) that adaption of inflation targeting in December 1992 in UK represent monetary policy break.

\section{Conclusion}

This paper focused on the term structure of interest rates for the G7 countries. Empirical validity of the expectation hypothesis is investigated by examining cointegration relationship between short- and long-term interest rates. For this purpose, we employed both linear and nonlinear cointegration tests. The results of the conventional linear cointegration tests support the validity of the expectation hypothesis for five countries, namely for Canada, France, Italy, Japan, and the USA, but not for the UK and Germany. Bearing in the mind the facts that various transaction costs as well market failures or asymmetric preferences of monetary authorities may give rise to nonlinearities in the adjustment process, we also applied nonlinear cointegration test developed recently by Kapetanios et al. (2006). We find that allowing for nonlinear adjustment results in rejection of the null hypothesis of no cointegration in six countries, namely in the cases of Canada, France, Italy, Japan, the UK, and the USA. The results of both linear and nonlinear tests suggest no cointegration for Germany, implying that the expectation hypothesis might not be a useful framework to analyze interest rate dynamics in this country. Our results have clear policy implications. Recently, central banks have used the short-term interest rate as a main instrument. In order to affect future spending decisions and inflation rate, central banks should be able to influence long-term rates through the operations of the short-term rates. The presence of a cointegration relationship between short- and long-term interest rates imply that monetary authorities may in fact affect real economic variables using interest rate tool. In addition, as the results of the 
nonlinear cointegration test suggest, the effects of monetary policy might be asymmetric, especially in the case of UK. Overall, our findings imply that when analyzing interest rates one might be cautious and take account of possible nonlinearities. Future research might analyze the sources of these nonlinearities.

\section{References}

Anderson, H. M. (1997). Transaction Costs and Non-Linear Adjustment Towards Equilibrium in the US Treasury Bill Market. Oxford Bulletin of Economics and Statistics, 59(4), 465-84.

Bachmeier, L. \& Li, Q. (2002). Is the Term Structure Nonlinear? A Semi parametric Investigation. Applied Economics Letters, 9(3), 151-53.

Balke, N. S. \& Fomby, T. (1997) Threshold Cointegration. International Economic Review, 38(3), 627-43.

Bernard, H. \& Gerlach S. (1996) Does the Term Structure Predict Recessions: The international Evidence. BIS Working Paper, No. 3.

Bianchi, F., Mumtaz, H. \& Surico, P. (2009). The Great Moderation of the Term Structure of UK Interest Rates. Journal of Monetary Economics, 56, 856-871.

Campbell, J. Y. \& Shiller, R. J. (1987). Cointegration and Tests of Present Value Models. Journal of Political Economy, 95(2), 1062-88.

Caner, M. \& Hansen B. E. (2001). Threshold Autoregression with a Unit Root. Econometrica, 69(6), 15551596.

Caporale, G. M. \& Pittis, N. (1998). Term Structure and Interest Differentials as Predictors of Future Inflation Changes and Inflation Differentials. Applied Financial Economics, 8, 615-25.

Christiano, L. J. \& Eichenbaum, M. (1992). Liquidity Effects and the Monetary Transmission Mechanism. American Economic Review, 82(2), 346-53.

Clarida, R. H., Sarno, L., Taylor, M. P. \& Valente, G. (2006). The Role of Asymmetries and Regime Shifts in the Term Structure of Interest Rates. Journal of Business, 79(3), 1193-1224.

Enders, W. \& Granger, C. W. J. (1998). Unit Root Tests and Asymmetric Adjustment with an Example Using the Term Structure of Interest Rates. Journal of Business and Economic Statistics, 16(3), 304-11.

Enders, W. \& Siklos, P. L. (2001). Cointegration and Threshold Adjustment. Journal of Business and Economic Statistics, 19(2), 166-76.

Engle, R. F. \& Granger, C. W. C. (1987). Co-integration and Error Correction: Representation, Estimation and Testing. Econometrica, 55(2), 251-76.

Estrella, A. \& Hardouvelis, G. A. (1991). The Term Structure as a Predictor of Real Economic Activity. Journal of Finance, 46(2), 555-76.

Fama, E. F. (1990). Term Structure Forecasts of Interest Rates, Inflation and Real Returns. Journal of Monetary Economics, 25, 59-76.

Fama, E. F. \& Bliss, R. R. (1987). The Information in Long Maturity Forward Rates. American Economic Review, $77(4), 680-92$.

Gallagher, L. A. \& Taylor, M. P. (2001). Risky Arbitrage, Limits of Arbitrage and Nonlinear Adjustment in the Dividend-Price Ratio. Economic Inquiry, 39(4), 524-536.

Granger, C. W. J. \& Teräsvirta, T. (1993). Modeling Nonlinear Economic Relationships, Oxford University Pres.

Hansen, B. E. \& Seo, B. (2002). Testing for Two-Regime Threshold Cointegration in Vector Error Correction Models. Journal of Econometrics, 110, 293-318.

Hall, A. D., Anderson, H. M. \& Granger, C. W. J. (1992). A Cointegration Analysis of Treasury Bill Yields. Review of Economics and Statistics, 74(1), 116-26.

Hardouvelis, G. A. (1988). The Predictive Power of the Term Structure During Recent Monetary Regimes. Journal of Finance, 43(2), 339-56.

Hardouvelis, G. A. (1994). The Term Structure Spread and Future Changes in the G7 Countries. Journal of Monetary Economics, 33, 255-283.

Hu, Z. (1993). The Yield Curve and Real Activity. IMF Staff Papers, 40, 781-806.

Johansen, S. (1988). Statistical Analysis of Cointegration Vectors. Journal of Economic Dynamics and Control, 12(2-3), 231-54.

Johansen, S. \& Juselius, K. (1990). Maximum Likelihood Estimation and Inference on Cointegration- with Applications to the Demand for Money. Oxford Bulletin of Economics and Statistics, 52(2), 169-201. 
Kapetanios, G. \& Shin, Y. (2006). Unit Root Tests in Three-Regime SETAR Models. Econometrics Journal, 9(2), 252-278.

Kapetanios, G., Shin, Y. \& Snell, A. (2003). Testing for a Unit Root in the Non-Linear STAR Framework. Journal of Econometrics, 112(2), 359-79.

Kapetanios, G., Shin, Y. \& Snell, A. (2006). Testing for Cointegration in Non-Linear STAR Error Correction Models. Econometric Theory, 22, 279-303.

Kuo, S. H. \& Enders, W. (2004). The Term Structure of Japanese Interest Rates: the Equilibrium Spread with Asymmetric Dynamics. Journal of the Japanese and International Economies, 18(1), 84-98.

Leeper, E. \& Gordon, D. (1992). In Search of Liquidity Effect. Journal of Monetary Economics, 29(3), 341-69.

Maki, D. (2006). Non-linear Adjustment in the Term Structure of Interest Rates: a Cointegration Analysis in the Non-Linear STAR framework. Applied Financial Economics, 16, 1301- 1307.

Mankiw, N. G. \& Miron, J. A. (1986). The Changing Behavior of the Term Structure of Interest Rates. The Quarterly Journal of Economics, 101(2), 211-228.

Michael, P., Nobay, R. A. \& Peel, D. A. (1997). Transactions Costs and Nonlinear Adjustment in Real Exchange Rates: An Empirical Investigation. Journal of Political Economy, 105(4), 862-879.

Mishkin, F. S. (1990). What Does the Term Structure Tell us about Future Inflation? Journal of Monetary Economics, 25, 77-95.

Mustafa, M. \& Rahman, M. (1995). Cointegration Between US Short-Term and Long-Term Interest Rates (Both Nominal and Real). Applied Financial Economics, 5(5), 323-27.

Nelson, E. (2001). UK Monetary Policy 1972-97: A Guide Using Taylor Rules, CEPR Discussion Papers, 2931.

Phillips, P. C. B. \& Ouliaris, S. (1990). Asymptotic Properties of Residual Based Tests for Cointegration. Econometrica, 58(1), 165-193.

Psaradakis, Z., Sola M. \& Spagnolo F. (2004). On Markov Error Correction Models with an Application to Stock Prices and Dividends. Journal of Applied Econometrics, 19(1), 69-88.

Sarno, L. \& Thornton, D. L. (2003). The Dynamic Relationship Between the Federal Funds Rate and the Treasury Bill Rate: An Empirical Investigation. Journal of Banking and Finance, 27(6), 1079-1110.

Siklos, P. L. \& Wohar, M. E. (1996). Cointegration and the Term Structure: a Multicountry Comparison. International Review of Economics and Finance, 5(1), 21-34.

Taylor, M. P. (1992). Modeling the Yield Curve. Economic Journal, 102, 524-37. 